\title{
Retention and transport processes of particulate and dissolved micropollutants in stormwater biofilters treating road runoff
}

Kelsey Flanagan ${ }^{a}$, Philippe Branchu ${ }^{b}$, Lila Boudahmane ${ }^{a}$, Emilie Caupos ${ }^{a}$, Dominique Demare ${ }^{c}$, Steven Deshayes ${ }^{a}$, Philippe Dubois ${ }^{a}$, Laurent Meffray ${ }^{b}$, Chandirane Partibane ${ }^{a}$, Mohamed Saad ${ }^{a}$, MarieChristine Gromaire ${ }^{\mathrm{a}}$

aLEESU, UMR MA 102, École des Ponts, AgroParisTech, UPEC, UPE, Champs-sur-Marne, 6-8 avenue Blaise Pascal, Cité Descartes, 77455 Marne-la-Vallée Cedex 2, France. kelsey.flanagan@enpc.fr

${ }^{\text {b} C E R E M A, ~} 12$ Rue Léon Teisserenc de Bort, 78190 Trappes, France. philippe.branchu@cerema.fr

' IFSTTAR, Laboratoire Eau et Environnement- route de Bouaye CS4 - 44344 Bouguenais Cedex, France.

\section{Abstract}

Road runoff is contaminated by various micropollutants and may be treated using low impact development techniques, such as stormwater biofilters. Better understanding the processes, such as filtration, sorption and leaching, which affect pollutants in these systems is essential to reliably predicting treatment performance and optimizing system design. Field data from an in situ monitoring campaign, wherein dissolved and particulate concentrations of a wide range of micropollutants (trace metals, polycyclic aromatic hydrocarbons, bisphenol-A, alkylphenols and phthalates) were characterized in untreated road runoff and biofilter outlets for 19 rain events, are used to explore transport and retention processes. Although retention of the particulate phase of pollutants was generally quite effective, unusually high particle concentrations were observed at biofilter outlets for three winter events. Particle characterization in road runoff and outlet waters revealed that this degraded performance was due to poor filtration rather than particle erosion, which was attributed to the relative abundance of small $(<10 \mu \mathrm{m})$ particles during this period, along with possible preferential flows. Dissolved pollutants were less effectively removed in general. To better understand this behavior, field results were combined with laboratory sorption and leaching tests. Dissolved concentrations of trace metals were shown to be influenced by organic carbon; leaching from road-originated particles may also influence their transport. Removal of the dissolved phase of organic micropollutants was limited by the contamination of the filter media, either before installation or during the first period of operation, due to emissions from construction materials.

\section{Keywords}

Biofiltration, micropollutants, road runoff, low impact development, deicing salt, sorption

\section{Introduction}

Runoff from road surfaces is a threat to the quality of receiving water bodies (both surface and groundwater) due to its contamination by trace metals (Huber et al., 2016) and hydrocarbons, including polycyclic aromatic hydrocarbons or PAH (Kayhanian et al., 2012; Zhang et al., 2008), as well as a range of emerging organic micropollutants such as alkylphenols and phthalates (Björklund et al., 2009; Clara et al., 2010). As such, it is important to develop strategies for managing this pollution, which are adapted to both its diffused and intermittent nature.

Over recent decades, new paradigms for urban stormwater management, focused on controlling stormwater close to the source rather than rapid drainage, have gained in popularity. These approaches, known under various terms including low impact development (LID), sustainable drainage systems (SuDS) and water sensitive urban design (WSUD), often make use of vegetated areas to reduce runoff volumes by increasing infiltration and evapotranspiration (Fletcher et al., 2014). 
During infiltration in these systems, water quality is generally improved. When pollution management is of particular concern, as may be the case for runoff from heavily trafficked road surfaces, a major design objective of LID devices may be water quality improvement. One technique often used in these cases is that of biofiltration, also referred to as bioretention, which consists of a vegetated depression where water is temporarily stored before filtering through an engineered soil or filter media, before being collected by an underdrain or exfiltrated to surrounding soil (Davis et al., 2009). Design guidelines for these systems include recommendations for filter media composition and layering, sizing and drain configuration, and plant selection (CIRIA, 2015; B. Hatt et al., 2009; Prince George's County Department of Environmental Resources, 2007).

Similar processes occur in the soil of other LID devices, such as vegetative filter strips and swales, which may also infiltrate large proportions of runoff (Flanagan et al., 2017). As such, it may be desirable to design them with an objective of improving water quality during infiltration. For the purposes of this paper, we will refer to all of these systems as biofilters.

In biofilters, the particle-associated fraction of pollutants are expected to be retained by sedimentation and filtration, while dissolved pollutants may be removed by sorption. After retention, pollutants may be dissipated through volatilization, biodegradation, photodegradation, and accumulation in plant mass (LeFevre et al., 2014). These desirable processes may be combined with other unintended processes, including erosion of particles from the soil (Hsieh and Davis, 2005), exchanges between the particulate and dissolved phases (Maniquiz-Redillas and Kim, 2014), and leaching from filter media or construction materials (Chahal et al., 2016). In addition, some pollutants may be in complexed or colloidal forms (Bäckström et al., 2004; Nielsen et al., 2015), limiting their reactivity and increasing their mobility. A better understanding of the processes occurring in these systems is essential to improving their design (Clark and Pitt, 2012) and their representation in modeling approaches.

Most previous investigations of pollutant retention processes in biofilters have been column studies conducted in laboratory settings to characterize the retention of either particles (Li and Davis, 2008) or dissolved (Lim et al., 2015; Sun and Davis, 2007) pollutants separately. Although these studies elucidate the behavior of either phase of pollutants under ideal conditions, they may not always be representative of behavior in the complex environment of field systems and do not provide information as to possible interactions between the phases.

On the other hand, while a number of field studies have demonstrated the ability of biofilters to improve water quality for various pollutants (David et al., 2015; Davis, 2007; DiBlasi et al., 2009; B. E. Hatt et al., 2009; Hunt et al., 2008), very few distinguish between dissolved and particulate pollutant fractions (LeFevre et al., 2012). As the two phases are retained by different mechanisms, without this distinction, it is difficult to establish a link between in situ performance and any particular processes.

Flanagan et al. (2018) evaluated the in situ water quality performance of two biofilters with respect to a large number of global parameters and micropollutants in both the dissolved and particulate phases. This study has raised questions about the processes responsible for pollutant retention and transport, providing a rare opportunity to test hypotheses about these processes in a field setting. In particular, while removal of particles and associated pollutants was usually very effective, a period of poor particle removal was observed for three winter events following the application of deicing salt. In addition, throughout the study, the retention of the dissolved fraction was limited, with no clear relationship between organic pollutant hydrophobicity and performance, indicating that performance depends on some of the unintended processes discussed previously.

The objectives of the present paper are to make use of this data set, along with further characterizations of particles, filter media and biofilter construction materials, to evaluate 
hypotheses as to (1) the processes leading to degraded particle removal in winter, including (i) erosion of filter media particles, (ii) poor filtration of road particles, (iii) preferential flows, (iv) differences in particle size distribution and ( $v$ ) colloid dispersion caused by deicing salt and (2) the various processes responsible for the limited retention of the dissolved phase of pollutants including (i) equilibration with filter media, (ii) equilibration with TSS particles, (iii) chemical speciation and (iv) emissions from construction materials.

\section{Materials and Methods}

\subsection{Field study}

\subsubsection{Study site}

The study site includes two vegetated stormwater biofilters: a vegetative filter strip (VFS, constructed in September 2012) and a biofiltration swale (BFS, constructed in March 2016), both of which evacuate water from the RD 212, a highway located in an industrial zone of Compans, France in the Paris region (see Appendix A for a study site map). VFS drains a road catchment of $504 \mathrm{~m}^{2}$ and measures $1.8 \mathrm{~m}$ by $48 \mathrm{~m}$ (perpendicular and parallel to the road), while BFS drains $352 \mathrm{~m}^{2}$ and measures $0.5 \mathrm{~m}$ by $32 \mathrm{~m}$. At each site, water was collected from a drain beneath the filter media (a mixture of $60 \%$ lime sand and $40 \%$ loam top soil by volume with a sandy loam texture), located at a depth of $15 \mathrm{~cm}$ in VFS and $50 \mathrm{~cm}$ in BFS. Only BFS is lined. The quality of the water collected from each drain is compared to untreated road runoff (RR) collected from a reference catchment along the same road (Figure 1).

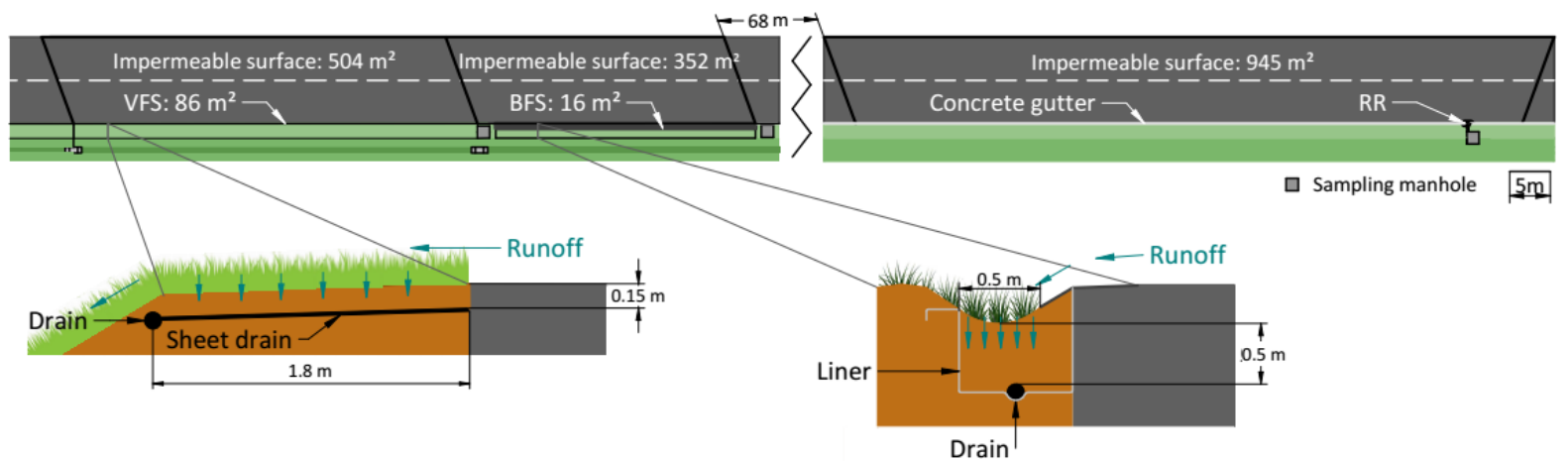

Figure 1: Compans study site

\subsubsection{Water sampling}

Details of the water sampling campaigns are available elsewhere (Flanagan et al., 2018). Briefly, composite event mean samples were collected in proportion to the flowrate, which was measured using tipping-bucket flow meters (17.4 L volume at RR, $1 \mathrm{~L}$ volume at BFS and VFS), using two refrigerated automatic samplers (Sigma SD 900 P) at RR and passive systems collecting a known fraction of every second bucket tip in the VFS and BFS drains. Sampling began in February 2016 for VFS and RR and in May 2016 for BFS and continued until July 2017 at all sites. Overall, 14, 15, and 18 samples were collected for RR, BFS and VFS, respectively, over a total of 19 rain events, spanning all four seasons. While the aim was to collect paired samples of inflow and outflow, due to different starting dates and technical difficulties, not all data are paired. Samples were collected immediately $(<24 \mathrm{~h})$ following the end of runoff flow and sent the same day to partner laboratories, where they were immediately filtered to distinguish between dissolved and particulate phases (when total and dissolved concentrations were analyzed, one aliquot was left unfiltered for total concentration analysis while the other was filtered for dissolved analysis). Sensors continuously measuring soil moisture content (Decagon EC-5 and EC-5 TE) were installed in the VFS ( 3 sensors above the sheet drain) and the BFS (15 sensors). 
Samples were analyzed for a range of global parameters and micropollutants, including $\mathrm{pH}$, conductivity, turbidity and all substances listed in Table 1 (see Appendix B for analytical methods). Phosphorus and Kjeldahl nitrogen were analyzed in the total and dissolved phases, while OC, metals, major ions and organic micropollutants were analyzed in the particulate and dissolved phases.

\begin{tabular}{|c|c|}
\hline Parameter & Substances and abbreviations \\
\hline Suspended solids & Total suspended solids (TSS) \\
\hline Organic carbon & Total organic carbon (TOC), Dissolved organic carbon (DOC) \\
\hline Nutrients & $\begin{array}{l}\text { Kjehldahl nitrogen }(\mathrm{KN}) \text {, Ammonium }\left(\mathrm{NH}_{4}^{+}\right) \text {, Nitrite }\left(\mathrm{NO}_{2}{ }^{-}\right) \text {, Nitrate }\left(\mathrm{NO}_{3}{ }^{-}\right) \text {, Phosphorus }(\mathrm{P}) \text {, Phosphate } \\
\left(\mathrm{PO}_{4}{ }^{3-}\right)\end{array}$ \\
\hline Trace metals & Arsenic (As), Cadmium (Cd), Chromium (Cr), Copper (Cu), Nickel (Ni), Lead (Pb), Vanadium (V), Zinc (Zn) \\
\hline Major elements & $\begin{array}{l}\text { Aluminum (Al), Iron (Fe), Manganese (Mn), Molybdenum (Mo), Strontium (Sr), Titanium (Ti), Sodium } \\
(\mathrm{Na}) \text {, Potassium (K), Magnesium (Mg), Calcium (Ca), Barium (Ba), Silicon (Si) }\end{array}$ \\
\hline TPH & Total petroleum hydrocarbons, $\mathrm{C}_{10}-\mathrm{C}_{40}(\mathrm{TPH})$ \\
\hline $\mathrm{PAH}$ & $\begin{array}{l}\text { 1-methyl Naphthalene (1MN), 2-methyl-Naphthalene (2MN), Acenaphthene (Acen), Acenaphthylene } \\
\text { (Acyl), Anthracene (A), Benzo[a]anthracene (BaA), Benzo[a]pyrene (BaP), Benzo[b]fluoranthene (BbF), } \\
\text { Benzo[g,h,i]perylene (BPer), Benzo[k]fluoranthene (BkF), Chrysene (Chry), Coronene (Cor), } \\
\text { Dibenzo[a,h]anthracene (DahA), Fluoranthene (Fluo), Fluorene (F), Indeno(1,2,3-cd]pyrene (IP), } \\
\text { Naphthalene (Nap), Phenanthrene (Phen), Pyrene (Pyr) }\end{array}$ \\
\hline BPA/AP & $\begin{array}{l}\text { Bisphenol-A (BPA), Para-nonylphenol (NP), Nonylphenol monoethoxylate (NP1EO), Nonylphenol } \\
\text { diethoxylate (NP2EO), Nonylphenol monocarboxylate (NP1EC), 4-tert-octylphenol (OP), Octylphenol } \\
\text { monoethoxylate (OP1EO), Octylphenol diethoxylate (OP2EO) }\end{array}$ \\
\hline PAE & $\begin{array}{l}\text { Dimethyl phthalate (DMP), Diisobutyl phthalate (DiBP), Dibutyl phthalate (DBP), Bis(2-ethylhexyl) } \\
\text { phthalate (DEHP), Dinonyl phthalate (DNP) }\end{array}$ \\
\hline
\end{tabular}

Table 1: List of studied substances and associated abbreviations

\subsubsection{Soil sampling}

A sample of BFS filter media was collected before installation; in addition, a soil sampling campaign was conducted in April 2017, after 13 months of operation. During this campaign, a cartography of the soil's surface contamination was established using X-ray fluorescence and used to identify eight zones of similar contamination for core sampling according to the method developed by Tedoldi et al. (2017). In each zone, 2-4 cores were collected, divided into three depth segments: 0-5 cm, 5-15 $\mathrm{cm}$ and $15-50 \mathrm{~cm}$, and combined to form composite samples for each depth. These cores were analyzed for the same elements and micropollutants as water samples.

\subsection{Evaluation of hypotheses as to processes affecting particles}

\subsubsection{Sources of outlet TSS}

To evaluate whether exceptionally high TSS concentrations in water drained from VFS or BFS were due to poor filtration of TSS in road runoff or the erosion of particles from the filter media, the source of outlet particles was evaluated by comparing particle composition. To do so, the concentrations of major and trace element concentrations in outlet TSS particles were compared with those in RR and the filter media. In order to account for the fact that large sand particles in the filter media, composed mainly (95.7\%) of $\mathrm{CaCO}_{3}$, are unlikely to be eroded, all concentrations were normalized to aluminum, which was assumed to be a major mineral component of the smaller soil particles, before this comparison. This comparison was carried out only for elements quantified in the majority of both soil and TSS samples.

\subsubsection{Preferential flows}

So as to consider whether exceptional preferential flows may have led to poor filtration during the period of degraded performance, the response times of each biofilter (defined as the time between the beginning of rainfall and the beginning of flow in each drain) was evaluated for every event. Response times for events with degraded performance were compared with those of normalperformance events, accounting for initial water content in the filter media (Appendix $\mathrm{H}$ ).

\subsubsection{Particle size distribution}

In order to consider whether particle size distribution (PSD) might explain differences in particle retention efficiency, PSD was compared between events from the period of poor performance and 
those of normal performance. It was also used to evaluate TSS concentration reductions by particle size. The particle size distribution (PSD) of TSS was evaluated for inlet and outlet water samples for events between January-July 2017 using laser diffraction particle size analysis (Mastersizer 3000). Due to technical difficulties and, in the case of outlet samples, TSS concentrations below the acceptable range for PSD analysis, PSD was analysed for 5 RR, 3 VFS and 3 BFS samples of the 9 collected within this period.

\subsubsection{Risk of colloid dispersion}

To specifically consider the role of deicing salt in leading to degraded performance, following the example of Norrström and Bergstedt (2001), the risk of colloid dispersion was evaluated by comparing observed SAR or sodium adsorption ratio (calculated according to Eq. 1 assuming dissolved concentrations of $\mathrm{Na}, \mathrm{Ca}$ and $\mathrm{Mg}$ to be in the ionic state) and electrical conductivity (EC), an easily measured surrogate for ionic charge, with guideline values used for assessing the risk of clay dispersion in agricultural soil from irrigation water (Shainberg and Letey, 1984).

$$
S A R=\frac{N a^{+}}{\sqrt{C a^{2+}+M g^{2+}}}
$$

Where SAR is the sodium adsorption ratio and $\mathrm{Na}^{+}, \mathrm{Ca}^{2+}$ and $\mathrm{Mg}^{2+}$ are ionic concentrations in $\mathrm{mmol} / \mathrm{L}$.

\subsection{Evaluation of hypotheses as to processes affecting dissolved pollutants}

The discussion of dissolved pollutants behavior focuses on a limited number of pollutants from each family which were frequently quantified in both the dissolved and particulate phases and for which partitioning data was available, either from batch tests using the initial BFS soil or in the form of $\mathrm{K}_{\mathrm{OC}}$ values from the scientific literature: $\mathrm{Zn}, \mathrm{Cu}, \mathrm{DEHP}, \mathrm{DBP}, \mathrm{NP}, \mathrm{OP}, \mathrm{BPA}, \mathrm{Pyr}$, Fluo and Phen. The analysis was limited to events within the period of normal particle retention. Correlations between parameters were evaluated using the non-parametric Spearman Rank Correlation Test.

\subsubsection{Equilibrium with filter media}

In order to evaluate whether equilibrium with soil drove dissolved concentrations observed at the BFS outlet, observed concentrations were compared with a range of those expected at equilibrium with the filter media according to Eq. 2 . This range was establishing using minimal and maximal filter media concentrations among the $15-50 \mathrm{~cm}$ segments and the initial sample. In order to establish a range of dissolved concentrations potentially at equilibrium with soil, minimal and maximal values among the $15-50 \mathrm{~cm}$ segments, along with the initial sample were retained. Samples from the top two segments were not used in this calculation in order to avoid a bias due to the surface contamination from particulate pollutants. Partition coefficients were evaluated experimentally or from the scientific literature as described below. For further details, see Appendix C.

$C_{D}=\frac{S}{K_{D}}$

Where $C_{D}$ is the dissolved concentration in $\mathrm{mg} / \mathrm{L}, S$ is the filter media concentration in $\mathrm{mg} / \mathrm{kg}$ and $K_{D}$ is the partition coefficient in $\mathrm{L} / \mathrm{kg}$.

\subsubsection{Experimental evaluation of partition coefficients}

Pollutant partition coefficients $\left(K_{D}\right)$, were determined in the lab for two trace metals commonly associated with the dissolved phase in urban runoff $(\mathrm{Zn}$ and $\mathrm{Cu}$ ) and three organic micropollutants common in the urban environment and for which the dissolved fraction can be significant: BPA, OP and NP (Gasperi et al., 2014). All tests were carried out using Evian mineral water diluted 1:4 with ultrapure water, which provided a $\mathrm{pH}$ and EC similar to those observed in field conditions outside periods of deicing salt application. 
Batch tests were conducted at several concentrations for each pollutant (Appendix D). For each test, $5 \mathrm{~g}$ of unused BFS filter media was equilibrated with $1 \mathrm{~L}$ of water for $24 \mathrm{~h}$. Following this period, a certain quantity of a given pollutant was added to reach the desired initial concentration; the system was then equilibrated by mixing constantly for $24 \mathrm{~h}$; a kinetic study of each pollutant confirmed that equilibrium was reached during this duration. Water was filtered and analyzed for dissolved concentrations; the change in concentration was assumed to be due to sorption to the media. The partition coefficient, $K_{D}$, was evaluated using only the points in the linear range of the isotherm. $\mathrm{NaN}_{3}$ was included in the BPA, NP and OP batch solutions to inhibit biodegradation.

Initial concentrations of $\mathrm{Zn}$ and $\mathrm{Cu}$ used in the batch experiments were selected to target equilibrium concentrations within the range of dissolved concentrations of these elements observed in the untreated road runoff.

To minimize analysis cost, the method of analysis used for BPA, OP and NP was different than the field method: samples were analyzed using high performance liquid chromatography with an ultraviolet detector (HPLC-UV) without a preliminary extraction. The limits of quantification (LOQ) of this method were relatively high $(55,170$ and $130 \mu \mathrm{g} / \mathrm{L}$ for BPA, OP and NP, respectively) compared to observed dissolved concentrations in the field. As such, the objective was to achieve equilibrium concentrations exceeding the LOQ that remained in the linear range of the isotherm. As at least 3-4 points for each pollutant were in the linear range, the range was considered acceptable for estimating a $K_{D}$ value. The resulting soil-water partition coefficients are 10250, 2500, 5, 43 and 230 $\mathrm{L} / \mathrm{kg}$ for $\mathrm{Cu}, \mathrm{Zn}, \mathrm{BPA}, \mathrm{OP}$ and NP, respectively.

\subsubsection{Evaluation of partition coefficients from the literature}

For a selection of organic pollutants from each pollutant family which were frequently quantified in both the dissolved and particulate phases (DEHP, DBP, NP, OP, BPA, Pyr, Fluo and Phen), organic carbon-water partition coefficients $\left(K_{O C}\right)$ were collected from the scientific literature and used to estimate $K_{D}$ from the filter media's organic carbon $\left(f_{o c}\right)$ content according to Eq. 3.

$K_{D}=K_{O C} f_{O C}$

Eq. 3

Between 12-91 $\mathrm{K}_{\mathrm{oc}}$ values were obtained in the literature for each pollutant (see Appendix $\mathrm{C}$ for full list of values and sources); the $20^{\text {th }}$ and $80^{\text {th }}$ percentile values for each pollutant were used to establish a $K_{O C}$ range, which was then used to establish a range of $K_{D}$. The laboratory-measured $K_{D}$ values for BPA, OP and NP all fell within the range predicted from $K_{o c}$ and the $f_{o c}$ of the initial filter media.

\subsubsection{Equilibrium with TSS particles}

In order to consider whether or not dissolved concentrations appear to be in equilibrium with particles in water samples, pollutant partition coefficients were evaluated for untreated road runoff, as well as in water drained from the BFS and the VFS. For organic pollutants, partition coefficients were normalized with the fraction of organic carbon $f_{o c}$ to evaluate $K_{o c}$ values, which are compared to the range $\left(Q_{20}-Q_{80}\right)$ of values from the literature (Appendix $C$ ). For metals, partition coefficients are compared to the minimal and maximal values from a data set of previously reported partition coefficients for road runoff (Appendix C).

\subsubsection{Leaching of trace metals from sediment or polluted soil}

In order to consider the potential for the remobilization of trace metals, leaching batch tests were conducted using road sediments and polluted soil. Sediment was collected from the road surface, while polluted soil was collected at the surface of the VFS at a distance of $30 \mathrm{~cm}$ from the road. Samples were collected in January 2016 and then dried, sieved, and homogenized before use in experiments. 
As with sorption batch tests, all tests were carried out using Evian mineral water diluted 1:4 with ultrapure water. $5 \mathrm{~g}$ of sediment or soil was equilibrated with $1 \mathrm{~L}$ of water for $24 \mathrm{~h}$. Initial concentrations of the soil and sediment were measured as were concentrations in filtered water after equilibration; the change in water concentration was assumed to be due to desorption from soil or sediment. Initial soil concentrations, dissolved concentrations at equilibrium and resulting partition coefficients are presented in Appendix E.

\subsubsection{Emissions from construction materials}

In order to consider the potential of organic micropollutant leaching from construction materials of the BFS (asphalt, an agricultural drain and its filter fabric and a geomembrane), batch leaching tests were conducted. These tests were also carried out using Evian mineral water diluted 1:4 with ultrapure water.

The drain, filter fabric and geomembrane samples employed for leaching tests had not been used prior to the tests. However, the asphalt was collected on site a year after its installation. Materials were placed in contact with water and agitated constantly for $24 \mathrm{~h}$ before being filtered and analyzed for BPA, alkylphenols and phthalates; PAH were also analyzed for the asphalt and geomembrane tests. Concentrations were compared to those in a reference batch with no material introduced. The filtrate was analyzed according to the same procedure as the dissolved phase of field samples except that double the volume was extracted for PAH analysis to lower the LOQ.

Liquid/solid ratios for leaching tests of the geomembrane, drain and filter fabric were selected to correspond to a low ratio that could be observed in situ, as would be observed for a small $(\sim 2 \mathrm{~mm})$ rain event. As the catchment drained by the BFS (including its own surface and side-slopes) is about $12 \mathrm{~m}$ wide, rain from a surface of about $12 \mathrm{~m}^{2}$ is expected to be drained by each linear meter of the BFS. Assuming a runoff coefficient of about 0.8 , about $20 \mathrm{~L}$ of runoff is expected to reach the BFS per linear meter. Thus, $1 \mathrm{~L}$ of water would be in contact with about $5 \mathrm{~cm}$ of each material.

Therefore, $5 \mathrm{~cm}$ of the drain and filter fabric were put in contact with $1 \mathrm{~L}$ of water. It was assumed that mainly the $50 \mathrm{~cm}$ width of geomembrane at the bottom of the BFS would be in contact with water; $500 \mathrm{~cm}^{2}$ of geomembrane was thus put in contact with $2 \mathrm{~L}$ of water. Both the drain and the geomembrane were cut into pieces (each approximately $2-3 \mathrm{~cm}^{2}$ ) to ensure their contact with water.

As the asphalt was collected on site a year after its installation, it was broken into pea-sized pieces before being put in contact with water to ensure that virgin surfaces were exposed. With this modified surface area, no clear relationship existed between a quantity of asphalt and water. The choice was made to put $200 \mathrm{~g}$ of asphalt in contact with $2 \mathrm{~L}$ of water.

\section{Results and Discussion}

\subsection{Mechanisms for the degradation of particle removal performance \\ 3.1.1. Description of the period of degraded performance}

Figure 2 shows concentrations of TSS, Zn and BaP observed in RR, BFS and VFS samples during normal functioning, compared with those during the period of degraded functioning, which occurred between January 9 and March 1, 2017. During normal functioning, concentrations of these pollutants in BFS and VFS were much lower and much less variable than those in RR. During the winter period, concentrations of these pollutants in the BFS and VFS drains, though still always lower than in RR, were much higher than those measured during the period of normal behavior. Concentrations in RR were also high during this period, though the difference compared to normal functioning was not as drastic as that observed at the outlets.

This period was notably cold $(13,19$ and 5 days with freezing minimal temperatures in December, January and February), and deicing salt was frequently applied to the road surface. It was also rather 
dry, with only 24, 29 and $34 \mathrm{~mm}$ of precipitation accumulated in December, January and February compared to 50, 52 and $47 \mathrm{~mm}$ on average (Météo-Paris, 2016), all of it in the form of rainfall rather than snow. However, despite low rainfall, humidity of the filter media during this period remained close to field capacity, presumably due to low evapotranspiration during the short days of winter. Therefore, the higher TSS concentrations observed at system outlets during this period cannot be explained by decreased water volumes.

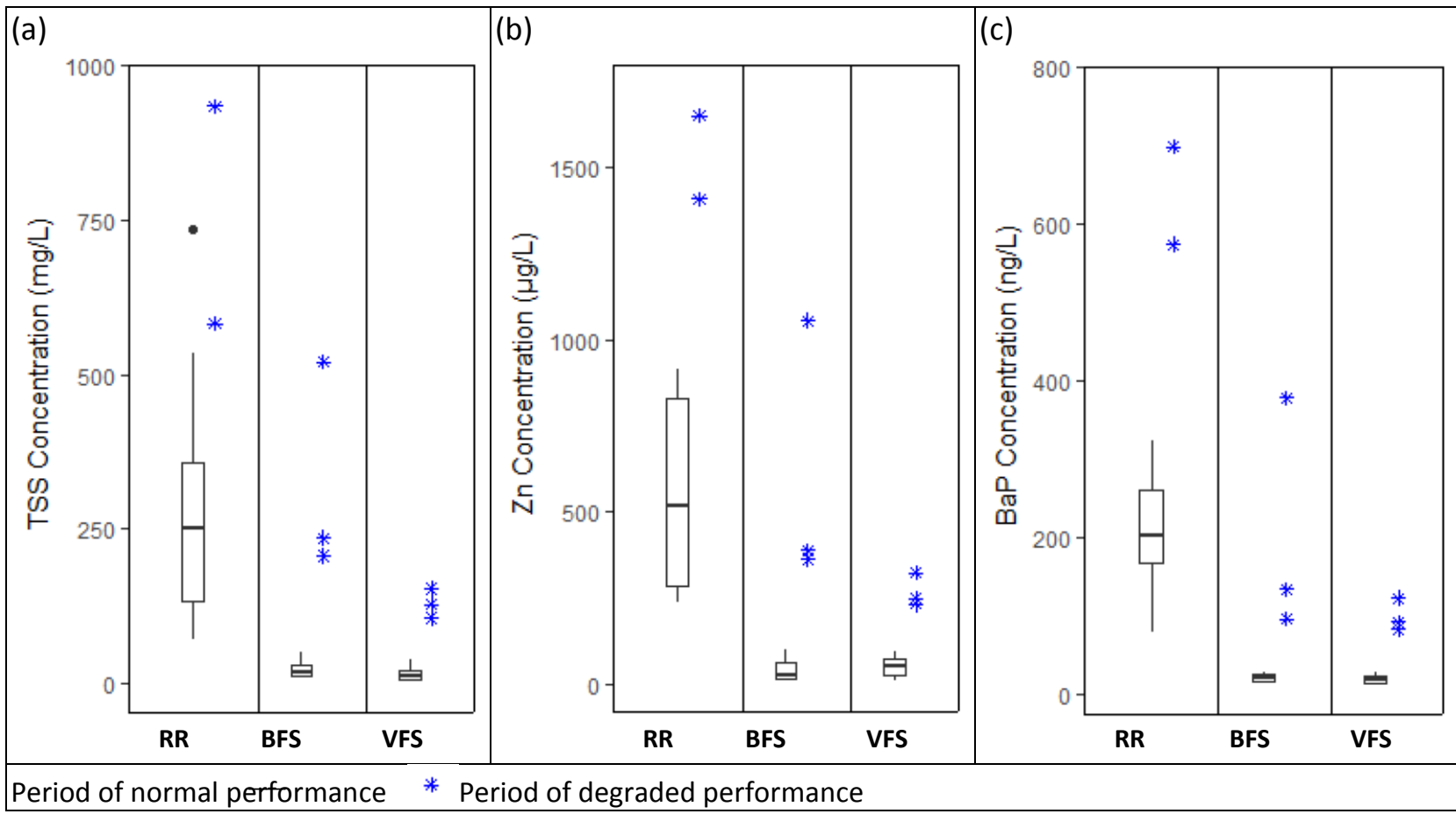

Figure 2: Comparison of concentrations observed during normal performance (boxplots) and degraded performance (blue stars) for (a) total suspended solids (TSS), (b) total Zn, (c) total benzo(a)pyrene (BaP) in road runoff (RR), the drain of the biofiltration swale (BFS) and the drain of the vegetative filter strip (VFS).

\subsubsection{Outlet particle sources}

As TSS is a mixture of particles of different origins and characteristics, elevated TSS concentrations in system drains could be caused either by the erosion of fine particles from the filter media or by an ineffective filtration of particles in road runoff. Understanding the sources of outlet TSS is an important first step to understanding the processes responsible for the degraded performance. Changes in the relative proportions of particles from different sources may be observed as evolutions in its elemental composition. If the erosion of fine particles from the filter media is responsible for the high outlet TSS concentrations during the period of poor performance, the elemental composition of outlet TSS during this period would be expected to approach the quality of this part of the soil as compared to the normal period. Conversely, poor filtration would be reflected by the quality of outlet TSS approaching that of RR TSS.

During the period of normal performance, the Al-normalized particle concentrations at the BFS outlet fall between those in RR and those in the filter media for most elements (Figure 3a), indicating that the outlet TSS is a combination of road-originated particles and fine particles eroded from the soil. Two exceptions to this are $\mathrm{Ca}$ and $\mathrm{Sr}$, for which concentrations decrease despite higher Al-normalized concentrations in the soil than in RR particles. As previously mentioned, the larger particles in the filter are mainly composed of $\mathrm{CaCO}_{3}$; this lime sand comes from the Boulonnais quarry in northern France, where $\mathrm{Sr}$ has been shown to be the most abundant trace element, present at concentrations between 0.10-0.64 mg/g (Debrabant, 1970). Therefore, this observation does not contradict the 
hypothesis that outlet particles are a mixture of road runoff and soil particles but indicates that these two species are more present in the less mobile sand particles than in the finer fraction of soil.

In the VFS during normal performance, Al-normalized trace element concentrations of outlet particles are closer to those in RR particles, while not all major elements ratios fall between those of RR particles and soil, indicating that soil particles make up a smaller proportion of outlet TSS (Figure 3c). Increases in some Al-normalized trace element concentrations in outlet particles compared to those in RR may be due to size differentiation in filtration; indeed, trace elements are usually considered to be preferentially associated with smaller particles (Kayhanian et al., 2012), which may be less efficiently retained in the filter. Less erosion of soil particles from the older VFS system than from the BFS, for which the filter media has not yet stabilized, may also explain the slightly lower TSS concentrations at the VFS outlet.

During the winter period, outlet particle quality appears to approach that of RR in both systems (Figures $3 \mathrm{~b}$ and $3 \mathrm{~d}$ ). This indicates that road-originated particles make up a higher proportion of outlet particles during this period and that poor filtration, rather than the erosion of clay particles is responsible for the high TSS contents at the outlet during this period. Non-normalized particle concentrations of all pollutant families can also been seen to approach those in RR during this period, further supporting the hypothesis of poor filtration (Appendix F). 


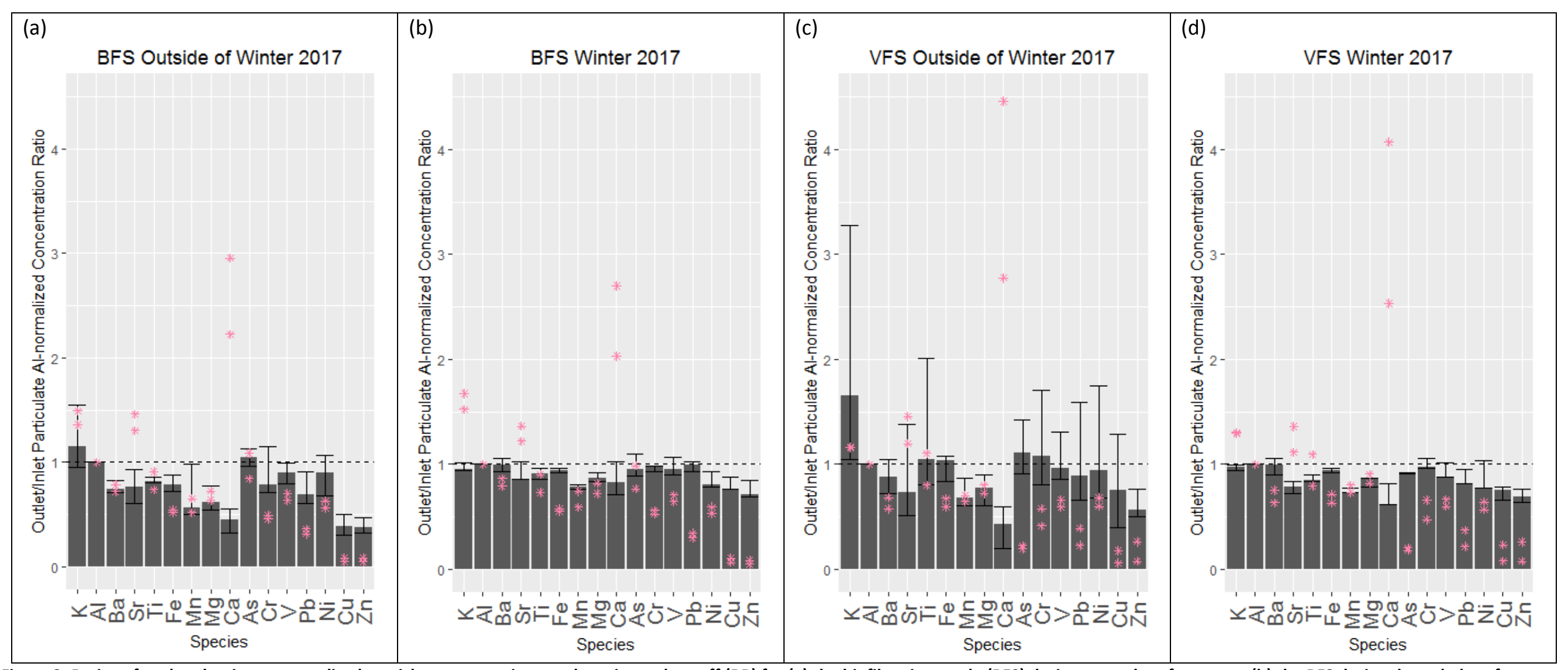

Figure 3: Ratios of outlet aluminum-normalized particle concentrations to those in road runoff (RR) for (a) the biofiltration swale (BFS) during normal performance, (b) the BFS during degraded performance in winter 2017, (c) the vegetative filter strip (VFS) during normal performance, and (d) the VFS during degraded performance in winter 2017. Bars represent the median ratio for each period, while error bars represent the $Q_{20}$ and $Q_{80}$ ratios during normal performance and the minimal and maximal values during degraded performance; the dotted line represents equivalency with RR values. Pink stars represent the $Q_{20}$ and $Q_{80}$ ratios of aluminum-normalized soil concentrations in each device to the median RR aluminum-normalized particle concentrations for each point and period. 


\subsubsection{Preferential flows}

A possible explanation of poor filtration during this period is filter media cracking, leading to the formation of preferential flows. Indeed, cracks were visible at the surface of the BFS during this period (Appendix G). Response times in the BFS for this winter period (11-115 minutes) were slightly shorter than those for other events with similar initial water contents (31-280 minutes), possibly indicating that some preferential flows may have occurred, especially during the January event corresponding to the 11-minute response time. As the soil was quite moist during this period, media cracking does not appear to be due to shrinking of dry soil; it could instead be due to expansion of water as it freezes. On the other hand, response times in the VFS were particularly long (95-708 minutes) compared to events with similar initial water contents (41-96 minutes), which does not support the hypothesis of preferential flows.

Preferential flows were more evident in both systems for the event of June 27, 2017, a summer event following a long dry period when the filter media appears to be cracked in both systems, leading to a very short response time (Appendix $\mathrm{H}$ ) and a short residence time (Appendix M). Although particle concentrations for this event were slightly elevated compared to other summer events, performance was not degraded to the same extent as during the winter period. Therefore, although preferential flows may contribute to poor filtration in the BFS in winter 2017, they do not appear to be the full explanation.

\subsubsection{Particle-size distributions}

Another element which may affect filtration efficiency is the RR particle size distribution (PSD). The PSD was evaluated for 5 events in RR, including two samples from the winter period and 3 samples from later in spring 2017, a period of normal performance (Figure 4). During the winter period, the volumetric proportion of colloids (particles $<10 \mu \mathrm{m}$ ) among RR TSS is high $(49-70 \%)$ compared to the other periods (7-16\%).

Particle size distributions were also available for two winter events and one spring event at outlets. The vast majority of TSS exiting the systems was associated with smaller particle sizes (Appendix I). In the BFS, lower concentration reductions were observed for the January 2017 event than for the other two events for all particle sizes ( $47 \%$ compared 87 and $94 \%$ in the case of particles $>10 \mu \mathrm{m}$ ), but especially for colloidal particles for which no reduction was observed $(-5 \%$, compared to 61 and $72 \%$ for spring events). This supports the hypothesis of preferential flows for this event.

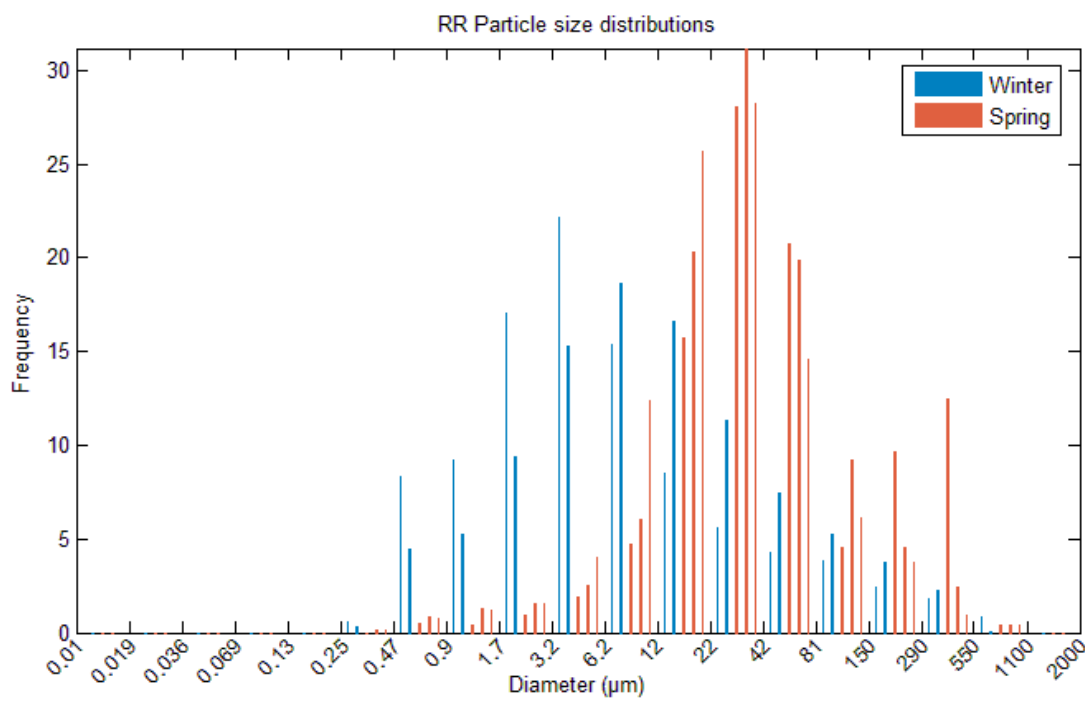

Figure 4: Total suspended solid particle size distribution by volume in road runoff. 
The smaller particle sizes of RR TSS during this period appear to be a major factor leading to poor filtration during the winter period. Colloidal particles are smaller than the pores in which most gravitational water flow occurs and are classically thought to be retained mainly by attachment rather than exclusion or straining processes (Yao et al., 1971). The difference in the filtration processes occurring may explain the observed differences in performance.

Although smaller TSS particle sizes in winter months have been reported previously for road runoff (Hilliges et al., 2017; Monrabal-Martinez et al., 2016), the mechanisms by which they occur are unclear. One hypothesis is that the particles formed during freezing conditions are different from those at other times of the year. For example, studded winter tires have been linked to the production of up to 100 times more < $10 \mu \mathrm{m}$ particles than summer tires (Sjödin et al., 2010). However, such tires are not commonly used in the Paris region where freezing temperatures are rare. In addition, as the chemical composition of road runoff particles does not significantly differ between the two periods (Appendix K), the balance between different particle sources appears to be relatively constant. Another hypothesis is that the same types of particles are formed but their agglomeration is modified by the application of $\mathrm{NaCl}$ deicing salt.

\subsubsection{Effects of deicing salt}

Deicing salt has previously been associated with high outlet particle concentrations in field (Winston et al., 2016) and column (McManus and Davis, 2017) studies of LID devices and may affect particle transport by interacting with colloids in RR or in the soil. According to the diffuse double-layer theory, cations form a layer around negatively charged colloidal particles; this double-layer creates a repulsive force between particles. As this layer becomes more compressed, the repulsive force decreases. Up to a concentration referred to as the flocculation value or critical coagulation concentration (CCC), adding an electrolyte will disperse colloids; beyond this point, it will lead to their flocculation as higher concentrations in solution compress the double-layer (Shainberg and Letey, 1984). CCC, which is expressed as ionic charge, increases with the proportion of sodium among the ions in solution or the SAR. (Goldberg, 1991; Shainberg and Letey, 1984). Therefore, although the addition of deicing salt increases ionic charge in RR, if it modifies the SAR enough that the CCC exceeds this ionic charge, it could disperse TSS colloids in RR water or clay particles in the filter media; this latter process could lead to media clogging or particle erosion (Shainberg and Letey, 1984).

The comparison of observed SAR and EC to ranges associated with a risk of clay dispersion in agricultural soil show that there is some risk of colloid dispersion in RR throughout the entire study period. The January-March period does not appear to be a period of particularly high colloid dispersion risk; instead, the highest risk occurs in spring months, when EC is especially low. Therefore, this criteria does not support the hypothesis that TSS colloids are dispersed in RR during this period more than others.

The water collected in the VFS and BFS drains also typically presents a slight to moderate risk of colloid dispersion. Again, the January-March period is not associated with a particularly high risk; in fact, in both systems, despite high SAR values, no colloid dispersion problems are predicted for the January event due to very high EC values. This also corroborates the hypothesis that high outlet particle concentrations during this period are due to poor filtration rather than particle erosion.

Generally, the dispersion of clays in soil is not expected during the arrival of high-sodium water due to high associated EC, but rather when non-saline water arrives in a soil system where Na has become the dominant base cation, leading to conditions with a high SAR and a low EC (Shainberg and Letey, 1984). In the present study, clay dispersion in the filter media does not appear to be a major problem for events following the period of salt application. SAR in outlet water decreases gradually along with EC; a severe risk of colloid dispersion was only observed for a single event with 
particularly low EC in June, when SAR levels were low. The apparent resilience of this filter media to deicing salt may be due to the fact that it contains large amounts of $\mathrm{CaCO}_{3}$, which tends to dissolve slightly during the filtration of runoff (dissolved Ca concentrations were systematically higher than those in RR in both systems), lowering the SAR and raising the EC of the water, thereby decreasing the risk of soil colloid dispersion. This being said, however, only a few events were sampled during each period; as such it is impossible to conclude that this behavior never occurs. In addition, the systems studied are relatively new $(<5$ years); more problems may arise as it ages.

It should also be noted that the criteria used to associate SAR and EC with a risk of colloid dispersion were established for soils in arid regions (Shainberg and Letey, 1984). As CCC also depends upon particle type, they may not be entirely applicable to the present system, particularly in the case of TSS particles in road runoff, which may be quite different from soil particles. Although it is beyond the scope of the present study, a specific characterization of CCC for road runoff particles at different SAR and different $\mathrm{pH}$ values would be useful to better understand the possible effects of deicing salt on TSS agglomeration.

\subsection{Processes affecting dissolved pollutants}

As previously mentioned, concentration reductions for dissolved pollutants were generally more limited than those observed for particulate pollutants. In addition, opposing trends were observed for trace metals and organic micropollutants. For trace metals, the newer BFS system tended to have a better performance than the VFS, for which dissolved concentrations in the outlet frequently exceeded those in RR (up to 205 and $94 \%$ for $\mathrm{Cu}$ and $\mathrm{Zn}$, respectively). To a lesser extent, BFS concentrations of these elements also occasionally increased compared to RR (up to 7 and $73 \%$, respectively). VFS tended to perform better than the BFS for organic pollutants; indeed, for several organic micropollutants, including DBP, DEHP, Pyr and Fluo, the first phase of operation of the BFS was a critical period, during which outlet dissolved concentrations sometimes exceeded those in RR by several hundred percent (Flanagan et al., 2018).

It should be noted that increases in concentrations measured in water drained from LID devices can sometimes be explained by the concentration of pore water between rain events due to evapotranspiration. This may be a factor in both biofilters, especially when the dry period between events is long. However, increases in dissolved concentrations of both trace metal and organic micropollutants were observed for events with short ( $<2$ day) dry periods and initial soil moisture near field capacity, indicating that other processes are also important to this phenomenon. In addition, the effect of evapotranspiration on outlet concentrations is limited by the amount of water which is lost to evapotranspiration between rain events. Soil moisture sensors showed that the highest water volume lost to evapotranspiration between rain events was $12 \%$ of the filter volume in either system, the equivalent of $2.3 \mathrm{~mm}$ of rainfall on the BFS catchment and $2.6 \mathrm{~mm}$ of rainfall on the VFS catchment. As such, water volume changes are not sufficient to explain concentration increases as large as those sometimes observed for trace metals in the VFS or for dissolved organic micropollutants in the BFS during the beginning of the study.

\subsubsection{Equilibrium with soil}

Sorption to soil particles is expected to be a major retention process for dissolved pollutants in stormwater biofilters (LeFevre et al., 2014). Models of reactive pollutant transport in soil often represent sorption as an instantaneous process, wherein an equilibrium exists between soil concentrations and dissolved concentrations according to a partition coefficient $\left(\mathrm{K}_{\mathrm{D}}\right)$, and/or as a kinetic process (Randelovic et al., 2016; Simunek and van Genuchten, 2006). Dissolved concentrations expected at equilibrium with the BFS filter media are compared to those observed in water drained from the BFS in Figure 5. 


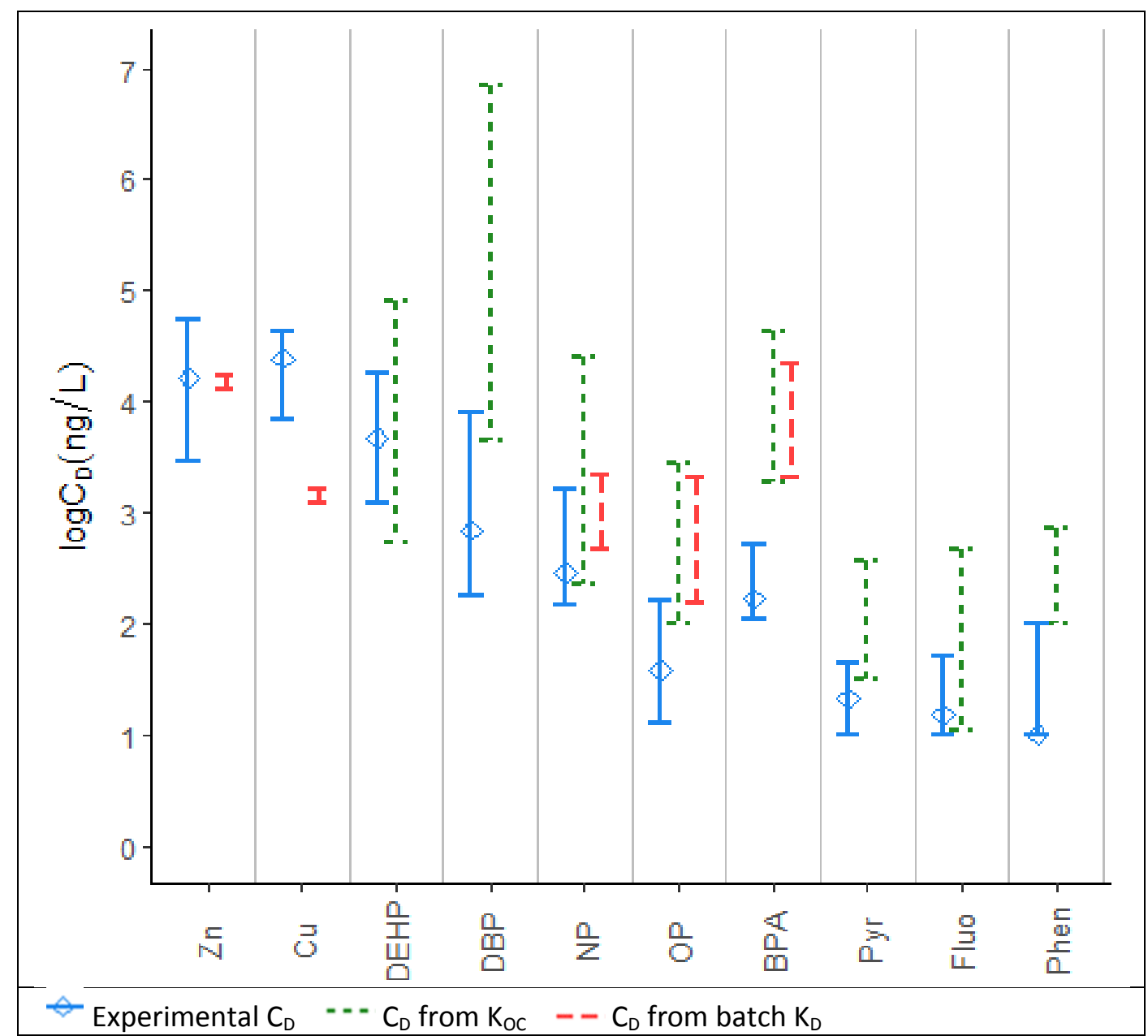

Figure 5: Dissolved concentrations estimated at the outlet of the biofiltration swale (BFS) assuming equilibrium with soil using $K_{o c}$ values from the scientific literature and batch $K_{D}$ compared to experimentally measured values. See Appendix $C$ for a detailed description of the assumptions, data and methods of figure production.

With the exception of the event occurring on June 27, 2017, for which filter media cracking following a long antecedent dry period led to an exceptionally short residence time of $1.9 \mathrm{~h}$, residence times in the BFS varied from 12 to 72 hours (Appendix M). According to sorption batch tests carried out for $\mathrm{Cu}, \mathrm{Zn}, \mathrm{BPA}, \mathrm{OP}$ and NP with unused BFS filter media, this duration should be sufficient for the infiltrating water to reach equilibrium with the soil. However, it can be seen that not all dissolved phase pollutants appear to be in equilibrium with the soil.

Indeed, dissolved concentrations of $\mathrm{Zn}$ are of the order of magnitude expected but more variable than expected at equilibrium with the soil, while those of $\mathrm{Cu}$ are also quite variable and higher than expected. While dissolved concentrations of some organic micropollutants (DEHP, NP, Fluo) are compatible with those expected, others (DBP, OP, BPA, Pyr and Phen) tend to be lower than expected at equilibrium with the soil.

\subsubsection{Processes affecting dissolved trace metals}

Besides the previously discussed effect of evapotranspiration, the increases in concentrations at system outlets might be explained by the leaching of trace metals from contaminated filter media or from accumulated sediments. Indeed, leaching batch tests showed that both contaminated soil and sediments were susceptible to leach $\mathrm{Cu}$ and $\mathrm{Zn}$ (Appendix E). However, both trace metals and sediment have previously been shown to accumulate near the surface of this system (Tedoldi et al., 2018). As such, the leached trace metals would have ample opportunity to resorb to the filter media 

$\mathrm{cm}$ in the VFS.

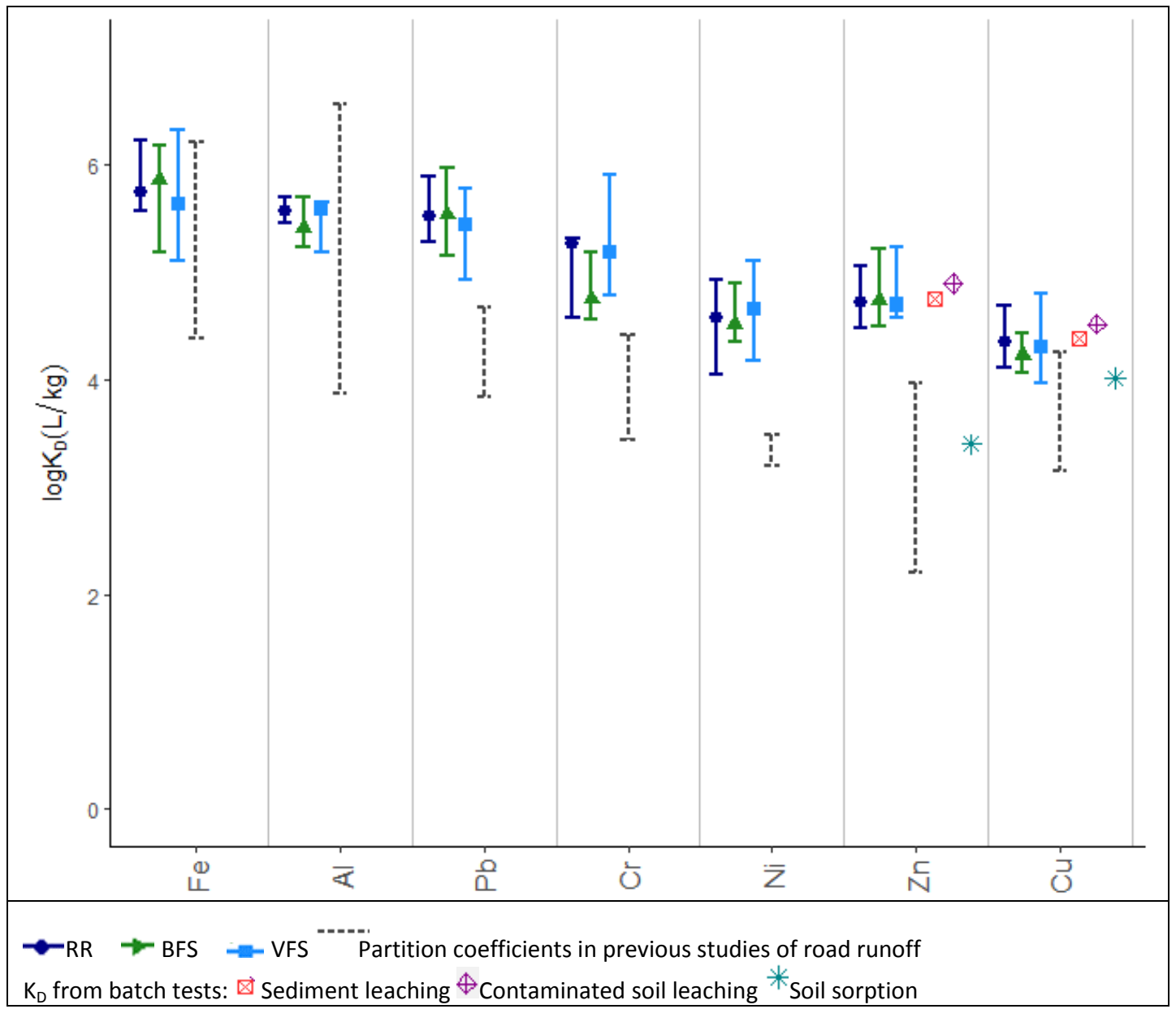

Figure 6: Partition coefficients for major and trace elements in road runoff (RR), outlet water from the biofiltration swale (BFS) and outlet water from the vegetative filter strip (VFS), compared to values from the scientific literature and partition coefficients measured in batch tests.

TSS particles (which are a mixture of road runoff particles and eroded soil) with non-negligible $\mathrm{Cu}$ (180-528 and 377-727 mg/kg in BFS and VFS, respectively) and Zn (471-1957 and 761-1925 mg/kg, respectively) content are present in drained water. If these particles reequilibrate with drained water after its filtration (in the bottle collecting drained water), they may also be sources of dissolved trace metals in collected outlet waters. This hypothesis is supported by the relatively constant trace metal partitioning (solid/liquid) between inlet and outlet waters (Figure 6); observed $K_{D}$ values are close to the values calculated from desorption tests from road sediments and polluted soil. However, this source is limited by the low TSS concentrations at outlets $(3-50 \mathrm{mg} / \mathrm{L}$, excluding events from the period of degraded TSS performance); therefore, it is unlikely that this hypothesis alone entirely explains dissolved concentrations observed at system outlets.

Dissolved metal transport may also be facilitated be their association with organic carbon or mineral colloids having particle sizes inferior to $0.45 \mu \mathrm{m}$ (pore diameter of filters used to separate the dissolved and particulate fractions before analysis), which may occur in runoff or be mobilized during filtration. For $\mathrm{Cu}$, this hypothesis is supported by the significant correlation $(\mathrm{P}<0.01)$ of dissolved concentrations with dissolved organic carbon (DOC) in the RR and at both VFS and BFS outlets (Figure 7a); this correlation is less evident for Zn (Figure 7b). Moreover, DOC also appears to influence the partition coefficient of both metals (Figure 7c-d), with a sharp decrease in $K_{D}$ observed when DOC increases. DOC may vary seasonally both in RR and outlet waters, with higher concentrations in 
warmer weather due to increased biological activity. In addition, DOC concentrations are nearly always higher at system outlets than in RR, probably due to degradation of organic matter within the biofilter, an effect which may increase as a system ages, due to more accumulation of organic matter. Increased DOC due to either of these causes may result in increased dissolved metal mobility (Appendix N).
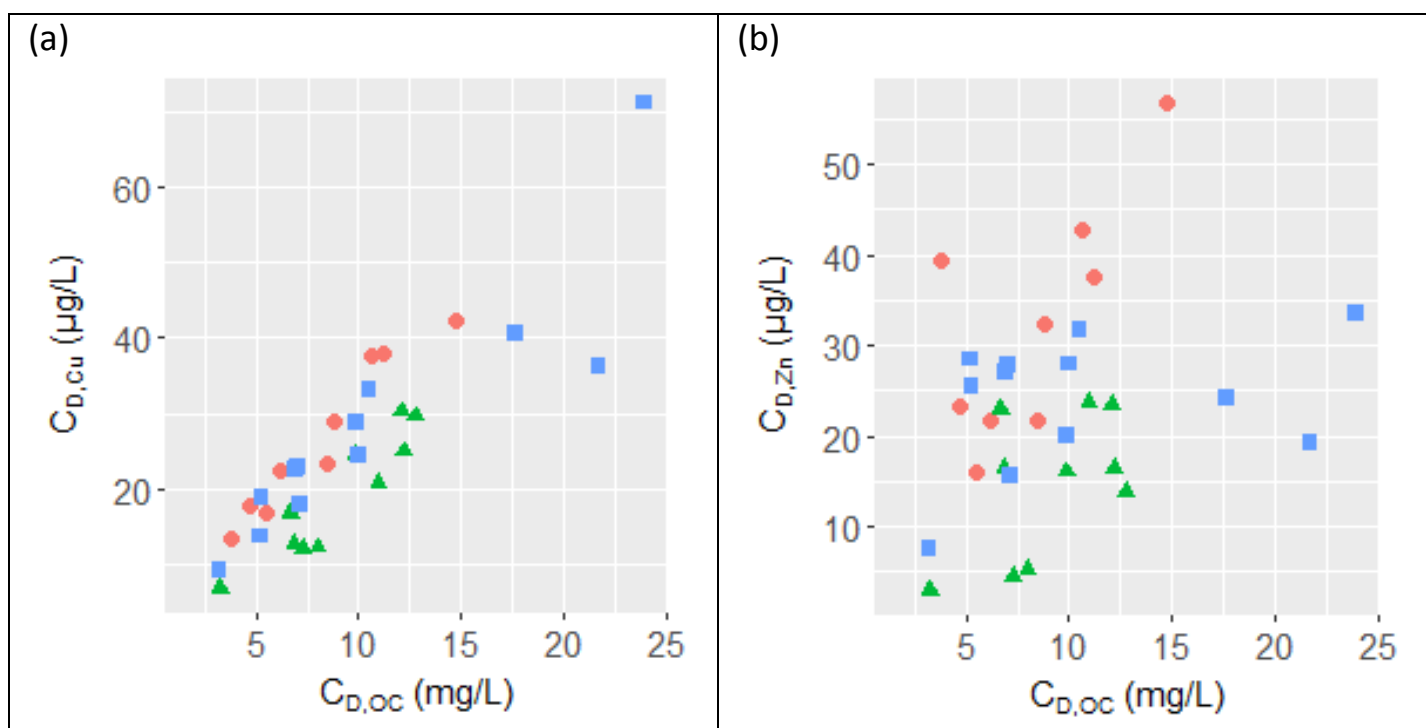

(c)

(d)
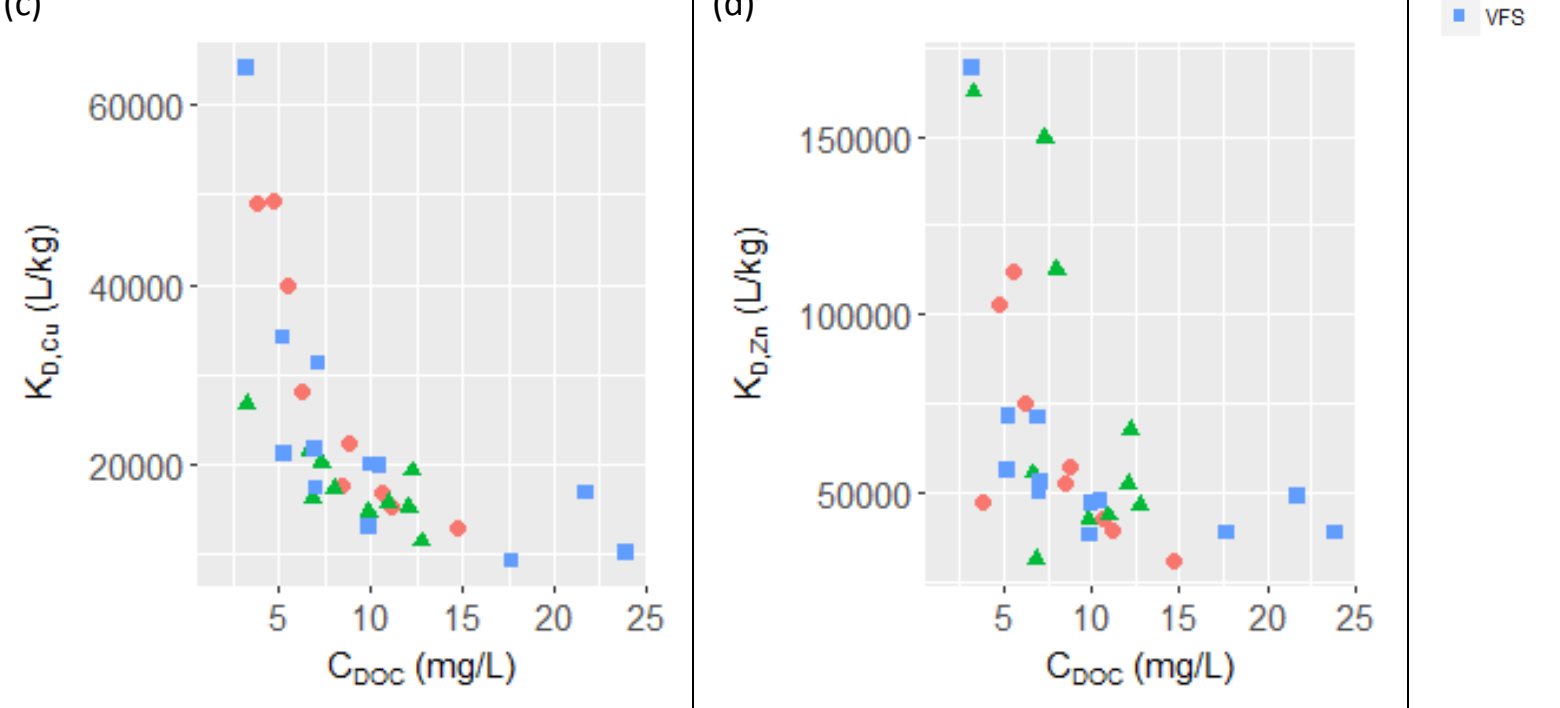

Figure 7: Correlations between (a) dissolved copper and dissolved organic carbon (DOC) concentrations, (b) dissolved zinc and DOC concentrations, (c) copper partition coefficients and DOC concentrations and (d) zinc partition coefficients and DOC concentrations in road runoff (RR), water drained from the biofiltration swale (BFS) and water from the vegetative filter strip (VFS).

\subsubsection{Processes affecting dissolved organic micropollutants}

As previously mentioned, the observed dissolved concentrations of organic contaminants were either compatible with or lower than values expected at equilibrium with the soil of the BFS. However, the system's performance removing these pollutants was poor; of the pollutants presented here, only Phen and OP were significantly removed across events (Flanagan et al., 2018).

The poor efficiency of the BFS system with respect to dissolved organic micropollutants may be explained by the high concentrations of these pollutants in its filter media. In the case of PAH, this appears to be to a contamination of the initial filter media $(0.146 \mu \mathrm{g} / \mathrm{g}$ for Pyr, $0.168 \mu \mathrm{g} / \mathrm{g}$ for Fluo and $0.072 \mu \mathrm{g} / \mathrm{g}$ for Phen). As these concentrations are typical for soil in lle-de-France (Gaspéri et al., 
2016), it is likely the contamination comes from the topsoil used to produce the filter media. On the other hand, the contamination of the filter media by DBP, DEHP, NP, OP and BPA, appears to have occurred mainly after its installation. In fact, a mass balance study of the BFS demonstrated an accumulation of DEHP, OP, NP and BPA in the filter, which greatly exceeded the mass of these pollutants intercepted from runoff over the first year of operation (Flanagan, 2018). The same study showed that mass of Pyr and Phen did not change significantly over the study period; mass balances were not evaluated for Fluo and DBP.

As phthalates, alkylphenols and BPA are common additives in many synthetic materials, pollution emissions were suspected from materials used in BFS construction, which included a geomembrane, an agricultural drain with a filter fabric and asphalt. Indeed, batch leaching tests of all of these materials revealed significant sources of DEHP, DBP NP, OP and BPA among these materials (Appendix O). The leaching of organic micropollutants from these sources explains both the elevated drain concentrations early in the BFS's operation and the contamination of the soil, as some of the leached contaminants were sorbed by the filter media. While the sorption of these pollutants to the filter media limits their exportation from the system and thus the potential for contamination of receiving waters, it also results in a lower performance of the system over time as the filter media is now essentially saturated with many of these pollutants.

As stated above, dissolved concentrations of DBP, OP, BPA, Pyr and Phen all tended to be lower than those expected at equilibrium with the soil. In addition, $C_{D}$ of these pollutants were typically lower at the outlet than in RR, at least after the first period of operation. One explanation for this may be that the reduction in concentrations of these pollutants is not due to sorption but rather to other processes. For example, DBP and BPA have biodegradation half-lives on the order of 1.4-16 days (Mackay, 2006)and 2.5-4 days (U.S. National Library of Medicine, 2018) respectively. As such, significant biodegradation may occur for DBP and BPA at the time scale of filtration.

As previously described, for Pyr and Phen, the filter media's contamination likely predates its installation in the filter. As desorption kinetics of organic molecules are known to become slow as pollution ages (Brusseau et al., 1991; Pignatello and Xing, 1996), this pollution is probably relatively immobile, leading to the an effective filter media $K_{D}$ which is higher than its theoretical sorption $K_{D}$, resulting in lower dissolved concentrations than those expected at equilibrium with the soil. Sorption processes may also not be entirely reversible for other organic micropolluants, for which the filter media was contaminated during the first period of operation through emissions from construction materials.

The dissolved phase of organic pollutants do not appear to be at equilibrium with TSS particles: no significant correlations were observed between $C_{D}$ and OC-normalized TSS particle concentrations $\left(S / f_{o c}, P>0.05\right)$ and observed $K_{o c}$ for TSS at all points were often higher than typical values from the literature (Figure 8) meaning that those pollutants' $C_{D}$ are low compared to those expected at equilibrium with the TSS particles. 


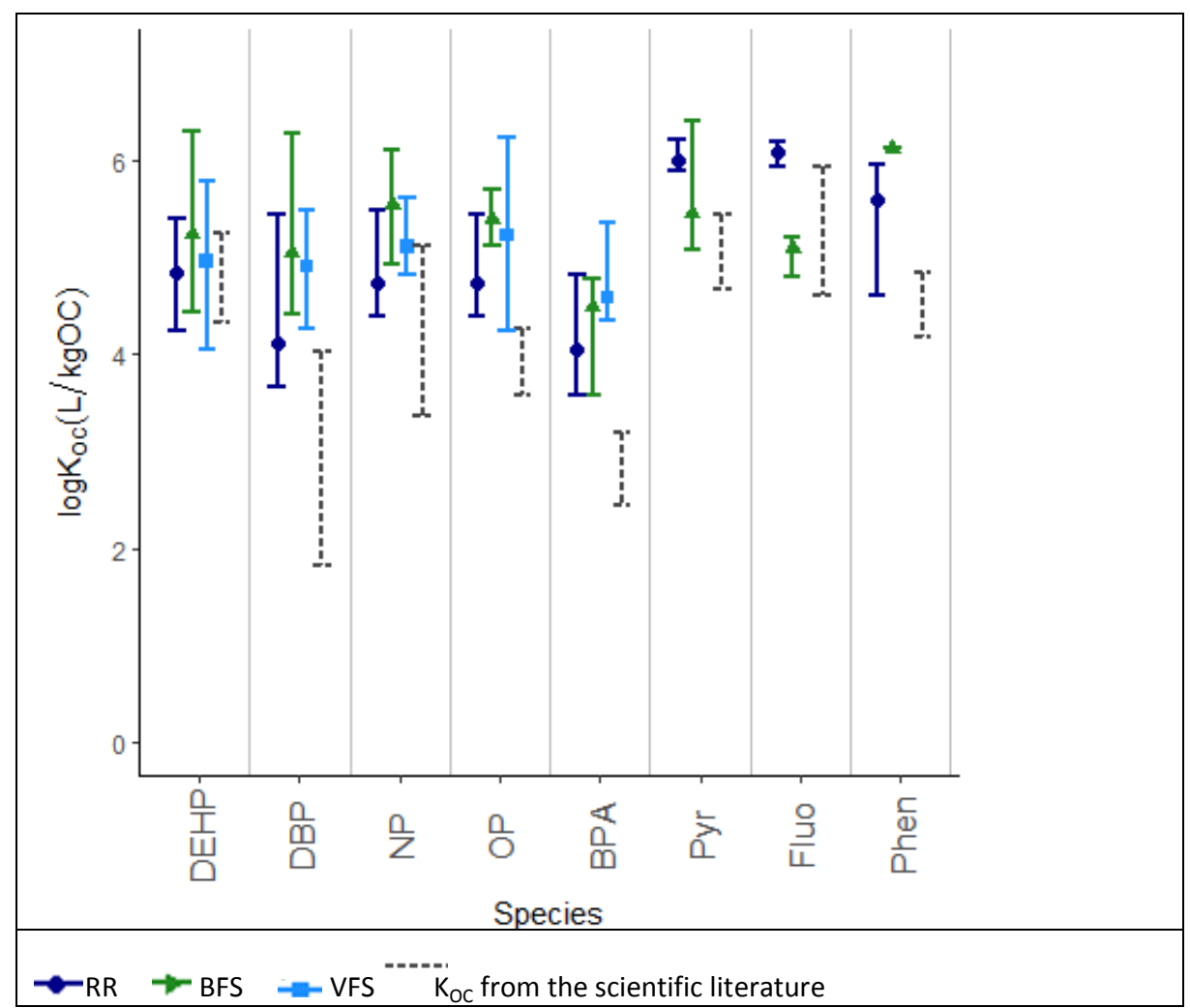

Figure 8: Partition coefficients for organic micropollutants (normalized to particle organic carbon content) in road runoff (RR), outlet water from the biofiltration swale (BFS) and outlet water from the vegetative filter strip (VFS), compared to values from the scientific literature (see Appendix $C$ for detailed information). Partition coefficients were not available for Pyr, Fluo and Phen in the VFS where these pollutants were rarely quantified in the dissolved phase.

One explanation for the non-equilibrium between TSS particles and dissolved pollutants could be that these pollutants are present within the materials making up the TSS and are thus not easily mobilized. For example, tire particles, thought to be major sources of $\mathrm{PAH}$, phthalates and alkylphenols in road runoff (Markiewicz et al., 2017), are likely to be particulate sources of these pollutants. In this case, pollutants are embedded in particle matrices; their dissolved concentrations would be controlled by leaching kinetics from this matrix and would not be expected to reach the same TSS-water equilibrium as initially dissolved pollutants. It can be seen that partition coefficients for PAH at the BFS outlet approach $\mathrm{K}_{\mathrm{Oc}}$ values, possibly due to the presence of soil particles which equilibrate with the dissolved pollutants.

\section{Conclusions}

The transport and retention processes affecting particulate and dissolved-phase micropollutants were evaluated for two stormwater biofilters treating road runoff based on results from an in situ monitoring campaign covering 19 events over 1.5 years, combined with additional characterizations of particles, filter media and biofilter construction materials.

Although the retention of particles and particulate contaminants was generally quite effective, over a 2-month period in winter during which deicing salt was applied, three events with degraded particle retention performance were observed. Particle characterization and evaluation of the risk of colloid dispersion indicated that poor filtration, rather than the dispersion and erosion of fine particles from the filter media, was responsible for the high outlet TSS concentrations during this period. This poor filtration was attributed to the relative abundance of very small $(<10 \mu \mathrm{m})$ particles in runoff during this period, which may have at times been combined with preferential flows due to filter media cracking. However, further research is needed to better understand the impact of this phenomenon on the device's pollutant interception performance at the annual scale. Continuous monitoring of 
turbidity in road runoff and in water drained from biofiltration devices would allow for a better characterization of the frequency and seasonality of degraded filtration performance. The mechanisms leading to smaller particle sizes could be better understood by visualizing particles with a scanning electron microscope during different seasons and by further characterizing the effects of SAR, ionic strength and temperature on the agglomeration of road-originated TSS in laboratory experiments.

Removal of dissolved pollutants was generally less effective than that of particles, despite the high adsorption capacity of the filter media measured in the lab. Dissolved concentrations of Cu were shown to be influenced by the presence of dissolved organic carbon, which likely modifies its chemical speciation. It was also demonstrated that road sediment and contaminated soil are both susceptible to leach $\mathrm{Zn}$ and $\mathrm{Cu}$, which may lead to increased outlet concentrations of dissolved metals under some conditions. Better characterizing the chemical speciation of trace metals in road runoff and in water drained from stormwater biofilters would enable a better understanding of their transport through these systems and their bioavailability in different types of water.

Removal of dissolved organic micropollutants appeared to be limited by the contamination of the background soil contamination in the Paris metropolitan area, were already too high to expect further reduction of the quite low dissolved PAH concentrations. This result demonstrates the importance of selecting a filter media with low initial contamination by the pollutants to be treated (or, on the contrary, adapting treatment objectives to background concentrations of a pollutant in the environment).

For other pollutants, including phthalates, alkylphenols and BPA, the filter media was contaminated during the first period of operation, due to emissions from construction materials (asphalt, drain, drain filter fabric, geomembrane). As these micropollutants are ubiquitous in synthetic materials, including such materials in the treatment device is counterproductive. Therefore, an infiltrating biofilter design with no synthetic materials is preferable to a drained design when these pollutants are of concern. As drainage may sometimes be necessary, it would be useful to establish standard protocols for evaluating emissions from materials as well as an archive of emission data from various materials in order to aide system designers in choosing the least polluting materials possible.

\section{Acknowledgements}

This study has been conducted within the framework of the Observatory of Urban Pollutants in Paris (OPUR) and the ROULÉPUR research program. The authors gratefully acknowledge the OPUR partners (AESN, SIAAP, CD92, CD93, CD94, Ville de Paris), the AFB (formerly ONEMA) and Seine Normandie Water Agency for financial support. We also acknowledge the Seine-et-Marne Departmental Council (CD77), and especially Eric Thomas and Tina Ratovelomanana, for their partnership and technical support. We would like to thank Tianran Dong, Delphine Truong, Thi Kim Phung Nguyen, Meriem Kajeiou and Maria Vitart de Abreu Lima for their work on the field campaigns and/or sorption tests. We also thank Béatrice Bechet for her participation in discussions about particle size distributions and their interpretation and Damien Tedoldi for his ideas about sorption and desorption processes.

\section{References}

Bäckström, M., Karlsson, S., Bäckman, L., Folkeson, L., Lind, B., 2004. Mobilisation of heavy metals by deicing salts in a roadside environment. Water Res. 38, 720-732. https://doi.org/10.1016/j.watres.2003.11.006

Björklund, K., Cousins, A.P., Strömvall, A.-M., Malmqvist, P.-A., 2009. Phthalates and nonylphenols in urban runoff: Occurrence, distribution and area emission factors. Sci. Total Environ. 407, 4665-4672. https://doi.org/10.1016/j.scitotenv.2009.04.040 
Brusseau, M.L., Jessup, R.E., Rao, P.S.C., 1991. Nonequilibrium sorption of organic chemicals: elucidation of rate-limiting processes. Environ. Sci. Technol. 25, 134-142. https://doi.org/10.1021/es00013a015

Chahal, M.K., Shi, Z., Flury, M., 2016. Nutrient leaching and copper speciation in compost-amended bioretention systems. Sci. Total Environ. 556, 302-309. https://doi.org/10.1016/j.scitotenv.2016.02.125

CIRIA, 2015. The SuDS Manual (C753). London.

Clara, M., Windhofer, G., Hartl, W., Braun, K., Simon, M., Gans, O., Scheffknecht, C., Chovanec, A., 2010. Occurrence of phthalates in surface runoff, untreated and treated wastewater and fate during wastewater treatment. Chemosphere 78, 1078-1084. https://doi.org/10.1016/j.chemosphere.2009.12.052

Clark, S.E., Pitt, R., 2012. Targeting treatment technologies to address specific stormwater pollutants and numeric discharge limits. Water Res. 46, 6715-6730. https://doi.org/10.1016/j.watres.2012.07.009

David, N., Leatherbarrow, J.E., Yee, D., McKee, L.J., 2015. Removal Efficiencies of a Bioretention System for Trace Metals, PCBs, PAHs, and Dioxins in a Semiarid Environment. J. Environ. Eng. 141, 04014092. https://doi.org/10.1061/(ASCE)EE.1943-7870.0000921

Davis, A.P., 2007. Field Performance of Bioretention: Water Quality. Environ. Eng. Sci. 24, 1048-1064.

Davis, A.P., Hunt, W.F., Traver, R.G., Clar, M., 2009. Bioretention technology: Overview of current practice and future needs. J. Environ. Eng. 135, 109-117.

Debrabant, P., 1970. Typologie géochimique des calcaires: Application à l'étude de l'origine des calcaires métamorphiques des Massifs hercyniens français (PhD). Faculté des Sciences de Lille.

DiBlasi, C.J., Li, H., Davis, A.P., Ghosh, U., 2009. Removal and Fate of Polycyclic Aromatic Hydrocarbon Pollutants in an Urban Stormwater Bioretention Facility. Environ. Sci. Technol. 43, 494-502. https://doi.org/10.1021/es802090g

Flanagan, K., 2018. Evaluation de la rétention et du devenir d'un panel diversifié de micropolluants dans un ouvrage de biofiltration des eaux de ruissellement de voirie (Thèse de doctorat). Université de Paris-Est.

Flanagan, K., Branchu, P., Boudahmane, L., Caupos, E., Demare, D., Deshayes, S., Dubois, P., Meffray, L., Partibane, C., Saad, M., Gromaire, M.-C., 2018. Field performance of two biofiltration systems treating micropollutants from road runoff. Water Res. 145, 562-578. https://doi.org/10.1016/j.watres.2018.08.064

Flanagan, K., Branchu, P., Ramier, D., Gromaire, M.-C., 2017. Evaluation of the relative roles of a vegetative filter strip and a biofiltration swale in a treatment train for road runoff. Water Sci. Technol. https://doi.org/10.2166/wst.2016.578

Fletcher, T.D., Shuster, W., Hunt, W.F., Ashley, R., Butler, D., Arthur, S., Trowsdale, S., Barraud, S., Semadeni-Davies, A., Bertrand-Krajewski, J.-L., Mikkelsen, P.S., Rivard, G., Uhl, M., Dagenais, D., Viklander, M., 2014. SUDS, LID, BMPs, WSUD and more - The evolution and application of terminology surrounding urban drainage. Urban Water J. 12, 525-542.

Gaspéri, J., Ayrault, S., Moreau-Guigon, E., Alliot, F., Labadie, P., Budzinski, H., Blanchard, M., Muresan, B., Caupos, E., Cladière, M., Gateuille, D., Tassin, B., Bordier, L., Teil, M.-J., Bourges, C., Desportes, A., Chevreuil, M., Moilleron, R., 2016. Contamination of soils by metals and organic micropollutants: case study of the Parisian conurbation. Environ. Sci. Pollut. Res. https://doi.org/10.1007/s11356-016-8005-2

Gasperi, J., Sebastian, C., Ruban, V., Delamain, M., Percot, S., Wiest, L., Mirande, C., Caupos, E., Demare, D., Diallo Kessoo Kessoo, M., Saad, M., Schwartz, J.J., Dubois, P., Fratta, C., Wolff, H., Moilleron, R., Chebbo, G., Cren, C., Millet, M., Barraud, S., C Gromaire, M., 2014. Micropollutants in urban stormwater: occurrence, concentrations, and atmospheric contributions for a wide range of contaminants in three French catchments. Environ. Sci. Pollut. Res. (8):5267-81. https://doi.org/10.1007/s11356-013-2396-0 
Goldberg, S., 1991. Flocculation of Illite/Kaolinite and Illite/Montmorillonite Mixtures as Affected by Sodium Adsorption Ratio and pH. Clays Clay Miner. 39, 375-380. https://doi.org/10.1346/CCMN.1991.0390406

Hatt, B., Morison, P., Fletcher, T., Deletic, A., 2009. Stormwater Biofiltration Systems: Adoption Guidelines.

Hatt, B.E., Fletcher, T.D., Deletic, A., 2009. Hydrologic and pollutant removal performance of stormwater biofiltration systems at the field scale. J. Hydrol. 365, 310-321. https://doi.org/10.1016/j.jhydrol.2008.12.001

Hilliges, R., Endres, M., Tiffert, A., Brenner, E., Marks, T., 2017. Characterization of road runoff with regard to seasonal variations, particle size distribution and the correlation of fine particles and pollutants. Water Sci. Technol. 75, 1169-1176. https://doi.org/10.2166/wst.2016.576

Hsieh, C., Davis, A.P., 2005. Evaluation and Optimization of Bioretention Media for Treatment of Urban Storm Water Runoff. J. Environ. Eng. 131, 1521-1531.

Huber, M., Welker, A., Helmreich, B., 2016. Critical review of heavy metal pollution of traffic area runoff: Occurrence, influencing factors, and partitioning. Sci. Total Environ. 541, 895-919. https://doi.org/10.1016/j.scitotenv.2015.09.033

Hunt, W.F., Smith, J.T., Jadlocki, S.J., Hathaway, J.M., Eubanks, P.R., 2008. Pollutant Removal and Peak Flow Mitigation by a Bioretention Cell in Urban Charlotte, N.C. J. Environ. Eng. 134, 403-408. https://doi.org/10.1061/(ASCE)0733-9372(2008)134:5(403)

Kayhanian, M., Fruchtman, B.D., Gulliver, J.S., Montanaro, C., Ranieri, E., Wuertz, S., 2012. Review of highway runoff characteristics: Comparative analysis and universal implications. Water Res. 46, 6609-6624. https://doi.org/10.1016/j.watres.2012.07.026

LeFevre, G., Paus, K.H., Natarajan, P., Gulliver, J.S., Novak, P.J., Hozalski, R.M., 2014. Review of Dissolved Pollutants in Urban Storm Water and Their Removal and Fate in Bioretention Cells. J. Environ. Eng. 141.

LeFevre, G.H., Hozalski, R.M., Novak, P.J., 2012. The role of biodegradation in limiting the accumulation of petroleum hydrocarbons in raingarden soils. Water Res. 46, 6753-6762. https://doi.org/10.1016/j.watres.2011.12.040

Li, H., Davis, A.P., 2008. Urban particle capture in bioretention media. I: Laboratory and field studies. J. Environ. Eng. 134, 409-418.

Lim, H.S., Lim, W., Hu, J.Y., Ziegler, A., Ong, S.L., 2015. Comparison of filter media materials for heavy metal removal from urban stormwater runoff using biofiltration systems. J. Environ. Manage. 147, 24-33. https://doi.org/10.1016/j.jenvman.2014.04.042

Mackay, D. (Ed.), 2006. Handbook of physical-chemical properties and environmental fate for organic chemicals, 2. ed., ed. ed. CRC/Taylor \& Francis, Boca Raton, Fla.

Maniquiz-Redillas, M., Kim, L.-H., 2014. Fractionation of heavy metals in runoff and discharge of a stormwater management system and its implications for treatment. J. Environ. Sci. 26, 12141222. https://doi.org/10.1016/S1001-0742(13)60591-4

Markiewicz, A., Björklund, K., Eriksson, E., Kalmykova, Y., Strömvall, A.-M., Siopi, A., 2017. Emissions of organic pollutants from traffic and roads: Priority pollutants selection and substance flow analysis. Sci. Total Environ. 580, 1162-1174. https://doi.org/10.1016/j.scitotenv.2016.12.074

McManus, M., Davis, A., 2017. Impact of periodic high concentrations of salts on bioretention nutrients performance. Presented at the International Conference on Urban Drainage, Prague.

Météo-Paris, 2016. Moyennes mensuelles des précipitations [WWW Document]. URL (accessed 5.17.18).

Monrabal-Martinez, C., Muthanna, T.M., Meyn, T., 2016. Seasonal variation in pollutant concentrations and particle size distribution in urban stormwater - design implications for BMPs. 9th Novatech conference: Planning \& technologies for sustainable urban water management, in: NOVATECH 2016. Presented at the Novatech. 
Nielsen, K., Erikkson, E., Strömvall, A.-M., Baun, A., 2015. Characterisation and Treatment of Nanosized Particles, Colloids and Associated Polycyclic Aromatic Hydrocarbons in Stormwater (PhD). Technical University of Denmark.

Norrström, A.-C., Bergstedt, E., 2001. The Impact of Road De-Icing Salts ( $\mathrm{NaCl}$ ) on Colloid Dispersion and Base Cation Pools in Roadside Soils. Water. Air. Soil Pollut. 127, 281-299. https://doi.org/10.1023/A:1005221314856

Pignatello, J.J., Xing, B., 1996. Mechanisms of Slow Sorption of Organic Chemicals to Natural Particles. Environ. Sci. Technol. 30, 1-11. https://doi.org/10.1021/es940683g

Prince George's County Department of Environmental Resources, 2007. Bioretention Manual.

Randelovic, A., Zhang, K., Jacimovic, N., McCarthy, D., Deletic, A., 2016. Stormwater biofilter treatment model (MPiRe) for selected micro-pollutants. Water Res. 89, 180-191. https://doi.org/10.1016/j.watres.2015.11.046

Shainberg, I., Letey, J., 1984. Response of Soils to Sodic and Saline Conditions. Hilgardia 52.

Simunek, J., van Genuchten, M., 2006. Contaminant Transport in the Unsaturated Zone Theory and Modeling, in: The Handbook of Groundwater Engineering. CRC Press, Boca Raton, Florida.

Sjödin, Ä., Ferm, M., Björk, A., Rahmberg, M., Gudmundsson, A., Swietlicki, E., Johansson, C., Gustafsson, M., Blomquist, 2010. Wear particles from road traffic - a field, laboratory and modelling study. Swedish Environmental Research Institute.

Sun, X., Davis, A.P., 2007. Heavy metal fates in laboratory bioretention systems. Chemosphere 66, 1601-1609. https://doi.org/10.1016/j.chemosphere.2006.08.013

Tedoldi, D., Chebbo, G., Pierlot, D., Kovacs, Y., Gromaire, M.-C., 2017. Assessment of metal and PAH profiles in SUDS soil based on an improved experimental procedure. J. Environ. Manage. 202, 151-166. https://doi.org/10.1016/j.jenvman.2017.06.063

Tedoldi, D., Flanagan, K., Chebbo, G., Branchu, P., Pierlot, D., Gromaire, M.-C., 2018. Zirconium deficit as a tracer of urban sediment accumulation in Sustainable Urban Drainage Systems Application to the calibration of a filtration model. Sci. Total Environ. 644, 941-953. https://doi.org/10.1016/j.scitotenv.2018.06.384

U.S. National Library of Medicine, 2018. Hazardous Substances Data Bank.

Winston, R.J., Davidson-Bennett, K.M., Buccier, K.M., Hunt, W.F., 2016. Seasonal Variability in Stormwater Quality Treatment of Permeable Pavements Situated Over Heavy Clay and in a Cold Climate. Water. Air. Soil Pollut. 227. https://doi.org/10.1007/s11270-016-2839-6

Yao, K.-M., Habibian, M.T., O'Melia, C.R., 1971. Water and waste water filtration. Concepts and applications. Environ. Sci. Technol. 5, 1105-1112. https://doi.org/10.1021/es60058a005

Zhang, W., Zhang, S., Wan, C., Yue, D., Ye, Y., Wang, X., 2008. Source diagnostics of polycyclic aromatic hydrocarbons in urban road runoff, dust, rain and canopy throughfall. Environ. Pollut. 153, 594-601. https://doi.org/10.1016/j.envpol.2007.09.004 